\title{
LA FUNDACIÓN DE LA PROVINCIA DE TALCA Y LA DIVISIÓN POLÍTICO-ADMINISTRATIVA DE 1826
}

\author{
Carlos Zúñiga Polanco \\ Pontificia Universidad Católica de Chile \\ crzuniga1@uc.cl
}

El proceso de consolidación de la independencia chilena tuvo muchas aristas, espacios y actores que determinaron su desarrollo exitoso. El problema de la historiografía tradicional es su aproximación marcadamente centralista el enfrentar el tema, olvidando la forma en que las regiones se desarrollaron en el proceso de construcción del Estado. El objetivo de este trabajo es analizar el rol que tuvo una ciudad intermedia como Talca, con una élite potente a nivel regional, indagando en la forma en que sus anhelos determinaron la toma de decisiones colectivas enfrentadas al periodo de ensayos constitucionales.

Esto se realizará mediante el análisis de los conflictos entre el Departamento de Talca y la capital, y de la división político administrativa de 1826, que posicionó a la ciudad de Talca en un rol secundario dentro de la provincia de Colchagua. El no ser designados como capital de la provincia provocó malestar entre los vecinos de la ciudad y generó un conflicto entre Talca, Curicó - la capital de la provincia-y Santiago, que tardó varios años en solucionarse.

Palabras Clave: Región, Estado, Construcción de Estado, Talca, Élite, Decisiones políticas.

\section{The foundation of the PRovinCE OF TALCA AND the POLITICAL-ADMINISTRATIVE DI- VISION OF 1826}

The process of consolidation of Chilean independence had many edges, spaces and actors that determined its successful development. The problem posed by traditional historiography has to do with the way of dealing with the issue, which has kept a markedly centralist tone, forgetting the way in which the regions developed in the process of state building. The objective of this paper revolves around the role played by an intermediate city such as Talca, with a powerful elite at the regional level, investigating the way in which their desires de-

[Recibido: 1/2/18; Aceptado: 3/7/18] 
termined the collective decision making faced with the constitutional trial period. This will be done, first, through the analysis of the conflicts between the Department of Talca and capital, and secondly, through the estudy of the political and administrative division of 1826 that positioned the city of Talca in a secondary role within the province of Colchagua. Not being designated as the capital of the province caused annoyance among the residents of Talca and generated a conflict between Talca, Curico - the capital of the province- and Santiago, which took several years to be solved.

KEYWORDS: Region, State, State Building, Talca, Elite, Decision making.

\section{Introducción}

El período de la historia chilena transcurrido entre 1818 y 1830 estuvo marcado por las diferentes disputas de poder entre militares, liberales, conservadores, federalistas y centralistas, que generaron un ambiente de desorden político dentro del país. Las disputas se originaron a raíz de temas ideológico-políticos, por la contraposición entre el gobierno de Santiago y el de las provincias, por el nombramiento de cargos públicos, la cantidad de representantes para el Soberano Congreso Nacional, así como también dado el fuerte autoritarismo inicial originado en la capital de la nueva república.

Proponemos que el conflicto suscitado en el departamento de Talca era un reflejo más de la poca coordinación y capacidad del nuevo orden republicano chileno luego de conseguida la independencia. El conflicto central de esta investigación, las demandas locales por la instauración de Talca como capital de provincia durante 1826, fue sinónimo de la inestabilidad y la poca acción de los gobiernos antes las constantes demandas provinciales. La tardanza en la resolución de este problema también evidenció la existencia de otras preocupaciones políticas, sociales y económicas que volvieron invisible el descontento existente entre los vecinos del departamento de Talca.

Es dentro de este contexto político de desorden y de diversidad de demandas ciudadanas en el país, donde analizaremos las tomas de decisiones políticas en un espectro local, con sus diferentes aristas. Para ello, se revisará e interpretará cómo se enfrentó la inestabilidad política y administrativa del país, en el Cabildo de Talca así como también en su Asamblea Departamental. Por esta razón, el objetivo de esta investigación es profundizar en las decisiones colectivas de los vecinos talquinos, frente a las decisiones políticas emitidas desde Santiago, teniendo como eje central la discusión en torno a la nueva división política administrativa emanada desde el Congreso y el Ejecutivo durante el año 1826. Veremos de esa forma que el conflicto poseía cierto nivel de complejidad que retrasó su eventual solución, vinculando temas políticos de representación nacional y, al mismo tiempo, aspectos relacionados con el honor y orgullo provincial proveniente del departamento de Talca.

El caso de la ciudad de Talca en el período post-independencia se enmarca en un contexto histórico político común en América Latina. El proceso de construcción estatal 
se vivió de distintas maneras en las nuevas repúblicas latinoamericanas, variando de acuerdo a las realidades coloniales heredadas en cada uno de los antiguos dominios monárquicos. El caso chileno se caracterizó por la fuerte hegemonía de la aristocracia crio$1 a^{1}$ que asumió el poder y la toma de decisiones tras la Independencia, con nula presencia de los sectores populares. ${ }^{2}$ Esta situación resulta particular respecto a lo estudiado para otros casos americanos.

El camino tomado por las ex colonias latinoamericanas en pos de construir un nuevo orden republicano estuvo marcado por diversos desafíos; en algunos casos territoriales, en otros de representatividad, y en otros, más llamativos, por conflictos socio-raciales. El ejemplo de las repúblicas andinas ha sido bien documentado y trabajado. Brooke Larson, entre otros, señala que los indígenas tuvieron un papel primordial en las independencias de Perú y Bolivia; sin embargo, sus sucesores se vieron afectados por una serie de discursos raciales propios del Estado modernizador que trastocaron la independencia de estos grupos indígenas campesinos. ${ }^{3}$ Florencia Mallon, quien analizó el fenómeno para México y Perú, apunta al mismo fenómeno, remarcando los mecanismos mediante los cuales el Estado logró ejercer una hegemonía sobre cuerpos indígeno-campesinos. En contrapartida, es posible destacar la formación de una cultura popular que se convirtió en una reacción campesina nacional a lo impuesto por el Estado-Nación mexicano y peruano en la segunda mitad del siglo XIX. ${ }^{4}$

Si se considera lo sucedido en las repúblicas andinas en comparación a Chile, podemos notar que la complejidad va de la mano de los actores partícipes del proceso de consolidación estatal. La diversidad de actores ralentiza el proceso y obliga a los Estados a construir un discurso que abarque mayores aspectos de la realidad social, económica y cultural de las distintas naciones. En Chile, la mayor complejidad, especialmente durante la década de 1820, estuvo relacionada con los disensos territoriales y de representación entre el gobierno y las élites provinciales. Es por ello que se deben ampliar los enfoques en torno a la construcción nacional y no conformarse con las visiones nacionales del mismo. ${ }^{5}$

1. Un ejemplo clásico del rol de la aristocracia en la construcción del Estado Nación en Chile y del control que esta ejercía sobre el aparato estatal es trabajado por Alberto Edwards en su «Fronda Aristocrática» donde recababa los mecanismos de la aristocracia chilena para amoldarse a sus instituciones para asegurar estabilidad y orden a la república. Edwards, Alberto, La fronda aristocrática de Chile, Santiago, Editorial Universitaria, 2012.

2. Grez, Sergio, De la regeneración del pueblo a la huelga general. Génesis y evolución histórica del movimiento popular en Chile (1810-1890), Santiago, Barros Arana, 1997. Salazar, Gabriel, Construcción de Estado en Chile: (1800-1837): democracia de los pueblos, militarismo ciudadano, golpismo oligárquico, Santiago, Editorial Sudamericana, 2005.

3. Larson, Brooke, Indígenas, Élites y Estado en la formación de las Repúblicas Andinas, Lima, Pontificia Universidad Católica del Perú. Fondo Editorial, 2002.

4. Mallon, Florencia, Campesino y Nación: la construcción de México y Perú poscoloniales, México D.F., Centro de Investigaciones y Estudios Superiores de Antropología social, 2003.

5. Se señala que la restitución «del papel de las regiones en la Construcción nacional, requiere una historiografía renovada. Una que, superando las limitaciones metodológicas de la historia local, conecte los procesos regionales al devenir del conjunto nacional», véase Cartes, Armando, Bíobio. Bibliografía histórica regional, Santiago, Dibam, 2014, p. 26. 
El caso de la ciudad de Talca es representativo de los desacuerdos provinciales que se vivieron durante la década de $1820 .{ }^{6}$ Estos desacuerdos tuvieron similitud con los experimentados luego del desmembramiento del Virreinato del Río de la Plata. José Carlos Chiaramonte se hace cargo de esta situación señalando que, para el caso de la temprana República Argentina, la inexistencia inicial de un Estado o de una nación llevó a la aparición de distintos intentos de organización estatal protagonizados primero por ciudades y luego por provincias. Estas se mantuvieron en constante beligerancia durante la década de 1820 , y en 1830 se produjo un momento en el cual Rosas, en un intento de unidad territorial, consolidó una confederación a pesar de la existencia de provincias soberanas e independientes al mando de caudillos locales. ${ }^{7}$

El lapso de tiempo transcurrido desde la fundación de la Villa de San Agustín de Talca, en el año 1742, hasta la emancipación se caracterizó por el establecimiento y consolidación de la ciudad y de su cabildo en el concierto nacional. Si bien la posición secundaria de Talca con respecto a Concepción y Santiago era inobjetable, fue durante el siglo XIX cuando ésta adquirió mayor importancia. A partir de 1810 la participación política de los notables talquinos tuvo una injerencia nacional, puesto que el momento histórico del país llevó a dar una mayor relevancia a las instancias locales de representación. De este modo, demandas nacionales y demandas locales se entrecruzaron generando conflictos de intereses directos.

La toma de decisiones políticas ha sido poco estudiado por los historiadores. ${ }^{8}$ Barbara Stolling, historiadora alemana, señala que el interés por la historia de la toma de decisiones es relativo a verlo como «un fenómeno comunicativo y, principalmente (pero no de forma exclusiva) como una acción colectiva». ${ }^{9}$ La toma de decisiones políticas es un momento que reúne a un grupo de personas diversas, con pensamientos e intereses distintos, que buscan un objetivo final acorde con sus experiencias y aspiraciones. De acuerdo a la misma autora el acto de decidir no es observable, es por eso que los historiadores han decidido dejárselo a los psicólogos. ${ }^{10}$ Por otro lado, James March propone que el resultado de la toma de decisiones grupales puede llegar a ser confuso, porque a veces «parecen traer a gente que no comparte nada más allá de la indiferencia hacia los deseos de unos y otros».11

6. Armando Cartes, historiador que hace énfasis en los enfoques regionales durante el período de Independencia y post-independencia, señala que «Los conflictos interprovinciales explican las tensiones de la Patria Vieja y los debates del período llamado de ensayos constitucionales; en los años siguientes, la incorporación o cooptación de fuerzas y líderes regionales por el gobierno central equilibró los intereses, lo que permitió la construcción de un Estado 'fuerte y centralizados', según la pretensión portaliana». Cartes, Armando, «Un gobierno de los pueblos...» Relaciones Provinciales en la Independencia de Chile, Valparaíso, Ediciones Universitarias de Valparaísco PUCV, 2014, p. 63.

7. Chiaramonte, José Carlos, Ciudades, Provincias, Estados: Orígenes de la Nación Argentina (1800-1846), Buenos Aires, Emecé, 2007.

8. Stollberg-Rilinger, Barbara, «Culture of decisión making» en The German historical Institute London, London, 2016, pp. 5-6.

9. Ibidem.

10. Ibidem.

11. Se sigue señalando que: «A veces parecen reflejar los la segunda opción de todos y no la primera elec- 
En esta misma línea, otro de los puntos relacionados es el concepto de poder en la toma de decisiones políticas. En esta teoría se define al poder como «la capacidad de obtener lo que quieres o satisfacer tu identidad», ${ }^{12}$ considerando que dentro de un grupo diverso muchos individuos «luchan, compiten y cooperan unos con otros tratando de satisfacer sus preferencias individuales e identidades». ${ }^{13}$ Es importante establecer cierta salvedad al momento de enfrentar los intereses de un colectivo, pues las decisiones, para casos como estos, deben centrarse en el punto medio de los numerosos intereses que gravitan alrededor. Es por ello que las distintas perspectivas políticas, culturales e ideológicas de los miembros de un grupo les llevan a buscar objetivos y resultados diferentes; no obstante, el aspecto a determinar es qué tan racionales son las decisiones tomadas tanto en grupo como individualmente, de acuerdo a lo que una comunidad política busca. En el caso de los vecinos talquinos, la decisión mezclaba elementos subjetivos y de identidad, así como también elementos objetivos y prácticos de la política nacional.

De este modo, el presente artículo aborda los dilemas que enfrenta el gobierno local en un contexto de inestabilidad nacional, teniendo como eje la unidad de los vecinos de la ciudad de Talca en la toma de decisiones políticas a inicios de la República. ${ }^{14}$ Así, en primer lugar se analizará la situación durante las revoluciones de Independencia, para luego detenernos en su actuar durante la primera década de vida independiente y, por último, se estudiará el modo en que el paso al régimen autoritario determinó la posición político-administrativa de Talca a nivel nacional.

\section{La revolución de Independencia, la élite y la acción local en Talca}

Habían transcurrido sesenta y ocho años desde la fundación de la Villa de San Agustín de Talca, y su espacio local se había transformado notoriamente dada su ubicación estratégica entre Santiago y Concepción. ${ }^{15}$ Esta fundación respondió a un proyecto mayor, en el marco de las reformas borbónicas, cuyo objetivo era alcanzar un mayor control territorial, otorgar facilidades comerciales y procurar la domesticación de los indígenas hostiles,

ción de alguien. A veces parece no estar implementados, o no estar implementados en forma de que cambie la decisión original. Ellos involucran complicadas combinaciones de confianza y desconfianza y inseguridades sustanciales que no son solo parcialmente resueltas en el proceso de decisión», March, James, «Multiple Actors. Conflict and politics», en A primer on Decision Making. How Decisions Happen, New York, 1994, p. 140 [traducción del autor].

12. March, James, Multiple Actors... cit., p. 141.

13. Ibidem.

14. Para este caso, la toma de decisiones políticas se verá de manera instrumental, dado lo variopinto de la asamblea departamental de la ciudad de Talca. Sin embargo es posible notar en las distintas posturas una unidad identitaria potente que va a ser la constante durante el período en cuestión.

15. Para conocer más en detalle de la fundación de la Villa de San Agustín de Talca, sus primeros años y su posicionamiento en el escenario del reino de Chile, consultar en Morales Yamal, Alejandro; Gonzalo Olmedo Espinoza y Raúl Sánchez Andaur, La villa de San Agustín de Talca. Origen y desarrollo entre la intención y la realidad (siglos XVI al XVIII), Talca, Universidad Autónoma-Gobierno regional del Maule, 2012. 
que durante el siglo XVIII seguían siendo una preocupación para las autoridades metropolitanas y coloniales. Las cédulas reales señalaban que las ciudades eran necesarias para favorecer la «vida social, política y cristiana ${ }^{16}$ en sus dominios. Para Gustavo Opazo, la idea estaba dirigida a poder ejercer un control más notorio de los espacios rurales, que hasta ese momento, en pleno siglo XVIII, se mantenían en la oscuridad y en el descontrol poblacional. ${ }^{17}$

Con la fundación de la villa de Talca se experimentó un impulso inicial de progreso que estuvo aparejado con la generación de redes sociales de poder, que en materia económica, por la iniciativa privada de las grandes familias — entre ellos estaban los Vergara, Donoso, Silva, De la Cruz y Pereira- ${ }^{18}$ posicionaron a Talca como un foco de desarrollo de la zona central del Reino de Chile. Su consolidación como espacio urbano se dio en 1796 cuando, desde Sevilla, don Nicolás de la Cruz y Bahamonde, descendiente del primer de la Cruz llegado a Chile décadas antes, obtuvo el título de ciudad para Talca. ${ }^{19}$

La crisis de la monarquía española, producto del ingreso de Napoleón a España y la abdicación de Fernando VII al trono a favor de José Bonaparte, se hizo sentir en América y en Chile durante el año 1808. En primera instancia las colonias americanas declararon su lealtad al rey Fernando VII, jurando no aceptar la autoridad de un rey extranjero, por lo que se movilizaron a favor de un autogobierno provisional hasta el regreso del monarca a sus funciones. Sin embargo, tanto en América como en Chile, por distintas razones, ${ }^{20}$ con el pasar de los meses el espíritu de lealtad cambió, ${ }^{21}$ y ya en 1810 se evidenciaba un cierto ambiente de inestabilidad social dentro las élites criollas, que anhelaban la participación y posesión de cargos políticos coloniales.

16. Opazo Maturana, Gustavo, Historia de Talca 1742-1942, Santiago, Imprenta Universitaria, 1942, p. 94.

17. «...Para remediar estas deficiencias propone un plan para aglutinar la población que consiste en formar un pueblo de españoles en el ámbito de cada curato, que deben fijar su residencia todos los habitantes de la jurisdicción». En Lorenzo, Santiago, Orígenes de las ciudades chilenas: las fundaciones del siglo XVIII, Santiago, Andrés Bello, 1983, pp. 19-20.

18. Opazo Maturana señala que estos dos troncos familiares no eran de origen español. Por un lado la familia De la Cruz se instaló en Chile a mediados del siglo XVIII con Giovanni de La Crocce, militar de origen genovés que sirvió a la corona española. Por otro lado, la familia Pereira, con Juan Albano Pereira Márquez, tenían origen portugués. Pereira fue comerciante y muy cercano a la familia De la Cruz por vínculos matrimoniales. En Opazo Maturana, Gustavo, Historia de..., cit., pp. 200-202.

19. Ibidem, p. 210.

20. En las Provincias Unidas del Río de la Plata, el espíritu de lealtad cambió por las anteriores invasiones británicas durante el año 1806 y la huida del Virrey a la ciudad de Córdoba, dejando a Buenos Aires en abandono. Fue este abandono el que llevó a la posterior deposición del virrey y el ascenso de Liniers en el cabildo de la capital virreinal, siendo el primer gobierno autónomo que paralelamente recibió noticias de la abdicación de Fernando VII. Ternavasio, Marcela, Historia de la Argentina 1806-1852, Buenos Aires, Siglo XXI, 2009, pp. 21 y ss. En Chile se realizaron juntas de gobierno con la aquiescencia del Consejo de Regencia durante 1810 y en 1811 se llamó a un Congreso Nacional de carácter moderado, hechos que reflejarían el tono moderado de algunos sectores de la sociedad chilena de aquel entonces. Lempérière, Annick, «¿Excepcionalidad chilena? La formación del Estado, entre revolución e institucionalización (1810-1845)», en Jaksic, Ivan y Francisca Rengifo (eds.), Historia Política de Chile, 1810-2010 Tomo II Estado y sociedad, Santiago, Fondo de Cultura Económica, 2018, p. 28.

21. Collier, Simon, Historia de Chile (1808-1994), España, Cambridge University Press, 1998, p. 40. 
En Chile, esto llevó a que en septiembre del mismo año se llamara a un cabildo abierto para evaluar la crisis de la Corona, y finalmente el 18 de septiembre de 1810 se concretó la Primera Junta Nacional de Gobierno, encabezada por el octogenario regidor: Mateo de Toro y Zambrano.

Los ecos de la Primera Junta Nacional se hicieron sentir en los distintos cabildos del Reino, y el día 4 de octubre de 1810 llegó a Talca la notificación de la Junta de Gobierno de Santiago. ${ }^{22}$ De inmediato la población reconoció el poder de dicha junta para dar al reino de Chile un gobierno interino. La élite local talquina, dividida ideológicamente, vivió divergencias políticas durante dicho período, aunque una mayoría considerable adoptó el ideal autonomista. ${ }^{23}$ En contraparte, una parcialidad de la familia de La Cruz, históricamente realista desde la llegada de don Nicolás de la Cruz y Bahamonde,$^{24}$ actuó como oposición a la presencia de grupos radicales que abogaban por la liberación del dominio español. Así, la divergencia que existió a nivel nacional entre realistas y radicales marcó también la política local en Talca y sus alrededores.

Existió un acuerdo mayoritario por parte de los vecinos para adoptar la causa independentista. De hecho, según Opazo, «hombres como José Ignacio Cienfuegos y don Casimiro Albano y Cruz, ambos presbíteros, supieron darle impulso a sus generosas ideas, arrastrando tras sí a sus numerosas parentelas y relaciones», señalando que la causa de la América «no era contraria a los preceptos de la religión». ${ }^{25}$

El desarrollo de las campañas de Independencia se llevó a cabo, principalmente, en los parajes ubicados entre Santiago y Concepción, teniendo a Talca como centro de operaciones militares. En respuesta al inicio de las hostilidades, desde Lima se enviaron contingentes militares a Concepción, comandados por el Brigadier español Antonio Pareja en marzo de 1813, quien tras numerosas victorias, logró extender sus líneas hasta el río Maule. ${ }^{26} \mathrm{El} 21$ de octubre de 1813, en pleno desarrollo de las primeras campañas militares, la Junta Nacional se trasladó a Talca, y más tarde nombró a Bernardo O’Higgins en reemplazo de José Miguel Carrera como comandante en jefe del ejército. ${ }^{27}$ Que Talca se convirtiera en sede de la Junta significó un reconocimiento político y estratégico a la posición de la ciudad como un espacio primordial en los acontecimientos que se desarrollaron durante la «patria vieja» (1808-1814).

Tras la derrota de los patriotas en Rancagua (octubre de 1814), se reinstauró el domi-

22. Archivo del Ministerio del Interior de Chile, vol. 13, fs. 2 (en adelante AMI).

23. Peter Guardino define esto como idea de «percepción de posibilidad» la cual grafica el deseo de las élites independientes por alcanzar objetivos políticos que habían sido acallados por siglos de dominación española, señalando que «el período después de la independencia fue un momento de gran fluidez en la vida social y especialmente en la vida política que primero parecía presentar oportunidades importantes para que varios grupos siguieran sus fines». Guardino, Peter, El tiempo de la Libertad. La cultura política popular en Oaxaca, 1750-1850, UABJO-UAM, 2009, p. 258.

24. Opazo Maturana señala que fue la familia Cruz la que tomó el poder político durante el período de la Reconquista. En Opazo Maturana, Gustavo, Historia de... cit., p. 231.

25. Opazo Maturana, Gustavo, Historia de... cit., p. 223.

26. Villalobos, Sergio, Historia de los chilenos Tomo 2, Santiago, Taurus, 2007, p. 27.

27. Collier, Simon, Historia ... cit., p. 43. 
nio español y comenzó la purga, encarcelamiento y posterior paso a la clandestinidad de los criollos patriotas en distintas ciudades del reino de Chile. En Talca la parcialidad de la Cruz, adepta al rey, recuperó el poder y su preeminencia, pasando a ser gobernador don Vicente de la Cruz y Burgos, quien con violencia y opresión intentó amilanar a los partidarios de la independencia ${ }^{28}$ en la zona del Maule.

Luego de 1814 muchos talquinos emigraron a Mendoza, y otros en la clandestinidad se adhirieron a la vanguardia libertadora, que en 1817 al mando de Ramón Freire atravesó la Cordillera de los Andes y se instaló en Teno, unos 80 kilómetros al norte de Talca. Ante las movilizaciones de tropas patriotas en la frontera, el gobernador Vicente de la Cruz y Burgos debió huir por la efervescencia social existente, ${ }^{29}$ dejando la ciudad a disposición de los patriotas. Así comenzaba en el Maule la etapa final de la revolución de Independencia. La búsqueda de la Independencia fue uno de los objetivos primordiales de la ciudadanía talquina, pues luego de la victoria en Maipú (abril de 1818), el cabildo talquino hizo un llamado a la firma de un documento titulado «Subscripción de los ciudadanos que votan por la necesidad de que el gobierno declare prontamente la independencia del Estado Chileno», ${ }^{30}$ en el cual firmaron varios centenares de ciudadanos a favor de la causa independentista.

En esta línea, se percibe una fuerte voluntad de unidad respecto a los procesos que se viven a nivel nacional en pos de adquirir la independencia de la monarquía española. En este conflicto de superposiciones primó la lealtad hacia la nueva figura de lo nacional por sobre lo local, identidad que generaría conflictos políticos, sociales y económicos. La nueva figura del Estado-Nación se introduciría en el pensamiento de los ciudadanos, en quienes aún persistiría la visión y el apego a un territorio que no iba más allá de la comarca colonial, resabios de un modelo colonial que más tarde colisionó con la nueva imposición estatal originada en la antigua capital del reino de Chile.

\section{La caída de O’Higgins y la voz de las provincias}

Una vez consolidada la Independencia, emergió el liderazgo algo cuestionado de Bernardo O’Higgins. Como Director Supremo de la República su principal misión fue organizar la Expedición Libertadora del Perú en conjunto con el general José de San Martín, a fin de expulsar a los últimos focos de resistencia realista en el territorio americano. En política exterior su gobierno fue exitoso, pero con el pasar de los años terminó por desencadenar una crisis política y social, principalmente entre la aristocracia nacional. ${ }^{31}$ Como

28. Opazo Maturana, Gustavo, Historia de..., cit., p. 231.

29. Ibidem, pp. 239-240.

30. AMI, 13, 60-65v. (Subscripción de los ciudadanos que votan por la necesidad de que el gobierno declare prontamente la independencia del Estado chileno, Abril 1818).

31. A esas razones políticas también se pueden sumar «las graves dificultades económicas provocadas por la guerra y el dislocamiento de la agricultura, el comercio y la administración». En Cartes, Armando, «Un gobierno de los pueblos...», cit., p. 297. 
resultado, se generó una fuerte oposición a la administración pública del gobierno de O'Higgins y, entre los sectores influyentes, se le reconoció como un régimen autoritario con fuerte presencia militar en sus escalafones más altos. Desde 1817 el gobierno central designó a los gobernadores provinciales, lo que en un inicio y dado el impulso independentista fue bien recibido por los poderes locales. Sin embargo, los modus operandi de la política local empujaron a los vecinos de distintas ciudades a plantear que los cargos públicos de administración local fuesen definidos entre los representantes de cada una de las ciudades del país. De este modo, y a partir de abusos y desavenencias surgidas entre gobernadores y representantes locales, comenzó a emerger resentimiento frente al gobierno de la capital por la paulatina limitación de atribuciones experimentadas por los ciudadanos de las provincias y los departamentos.

La renuncia de Bernardo O’Higgins en enero de 1823, de acuerdo a Simon Collier, «condujo al desmembramiento de las tres provincias de Chile. La primera tarea de cualquier gobierno era, por ende, el reunificarlas». ${ }^{32}$ Este desmembramiento provincial se debió al descontento generado por las políticas de corte autoritario que terminaron por asfixiar a las provincias, en materia de participación, atribuciones y competencias. ${ }^{33}$ Para Armando Cartes la renuncia de O'Higgins dio pie al inicio del «momento provincial» que se venía gestando desde 1822, producto de las malas cosechas, la guerra, la escasez, y un rechazo específico al ministro Rodríguez Aldea por sus vinculaciones realistas. ${ }^{34} \mathrm{El}$ rechazo ultramaulino ${ }^{35}$ también fue adoptado en Talca, que como colectividad apoyó la causa anti autoritaria, puesto que con el fin de éste régimen se podría consolidar la idea de libertad forjada durante el período de independencia. En efecto, había interés entre los vecinos de la ciudad por obtener una mayor cuota de participación en los asuntos y negocios públicos a nivel nacional.

En respuesta a la renuncia del Director Supremo, los habitantes de Talca elaboraron una declaración, en la cual se señaló que:

La innata proprención a la libertad solo inspira esta resolución y constancia, y quando después de tantas fatigas creíamos haver llegado al termino de tan agigantada empresa, hemos visto por desgracia que el gobierno de la Capital conducido por un egoísmo y ambición inexplicables ha

32. Collier, Simon, Ideas y política de la independencia chilena 1808-1833, Santiago, FCE, 2012, p. 263.

33. Esto de las divergencias provinciales se produjo teniendo como eje el rol de Santiago, la capital, como factor decisivo en la toma de decisiones a nivel nacional. Muchas de sus decisiones pasaban por alto las realidades locales. En América Latina el centralismo fue un fenómeno constitutivo de los procesos de consolidación estatal, incluso en países donde su conformación político administrativa era de corte federal. En las Provincias Unidas del Río de la Plata (futura Argentina), a pesar de la existencia de provincias del interior que se autogobernaban durante el período en cuestión, siempre fue Buenos Aires la provincia más rica y con mayores probabilidades de progreso. Una de las razones que se esbozan es su posición como puerto de salida a las mercancías, hecho por el cual generaba enormes riquezas por derechos aduaneros. Ver Ternavasio, Marcela, Historia de la... cit, pp. 119 y ss.

34. Cartes, Armando, Un gobierno de los..., cit., p. 298.

35. Cuando hablamos de «ultramaulino» hacemos referencia al existente más allá del río Maule, por aquel entonces el límite sur de la Provincia de Santiago y el límite norte de la Provincia de Concepción, provincia que durante el período fue foco de resistencia al poder gubernamental de Santiago. 
perseguido la virtud y el merito, y ollado los sagrados derechos de los pueblos: ha fallado a las promesas mientras ha sostenido la destructora guerra que ha embuelto en miserias y anegado en sangre la virtuosa provincia de Concepción... ${ }^{36}$

Los vecinos de la ciudad de Talca creían que el éxito de la independencia se vio amilanado por el autoritarismo, la perdida de libertad y de autonomía en la toma de decisiones de las provincias que habían sido escenario clave de la revolución. La ansiada libertad de los ciudadanos de todos los rincones del país se silenció con un régimen que prolongó hasta el período republicano la superposición de Santiago como epicentro del gobierno y del control político.

La convocatoria a una convención constituyente tras la caída de O'Higgins, desde Santiago, tuvo como fin poner orden y control al desorden provincial. Sin embargo, reconociendo las carencias e injusticias propias de un gobierno autoritario, Talca decidió alinearse con Concepción para posicionarse contra «aquellos [que] formaron a su combeniencia una constitución que toda ella estriva en la perpetuidad al Despotismo con manifiesto ultrage a la Nación». ${ }^{37}$

En la misma declaración los talquinos señalaron que «mientras todos los pueblos germinan bajo este yugo opresor; Talca sufría por la ominosa odiosidad del gobierno todos los males que estavan a sus alcanses», ${ }^{38}$ lo que llevó a que los ciudadanos tomaran una decisión final a través de su «unánime consentimiento y de su espontánea voluntad» a través de un «cavildo abierto el día diez y siete del presente, proclamando su libertad uniendo sus votos a los de la Asamblea de Concepción», ${ }^{39}$ jurando de esa forma defender, con determinación, la causa de la libertad de las provincias. Solo de esa forma se lograría «conseguir un gobierno electo por la voluntad libre a los pueblos por medio de sus representantes» ${ }^{40}$ Si bien Talca era parte de la Provincia de Santiago desde $1811,{ }^{41}$ esto no fue una razón de relevancia para que la ciudad decidiera escindirse de Santiago y alinearse con la Provincia de Concepción.

El cabildo de Talca tomó una decisión política debido a la paupérrima conducción que tuvo el gobierno de Santiago en materia política y administrativa con las provincias y sus representantes. Las guerras de independencia habían sido llevadas a cabo por el ideal de la libertad; libertad que hasta ese momento había sido coartada por el actuar del centralismo capitalino. A contar de ese momento Talca optó por dejar de participar de la asamblea provincial de Santiago y pasar a ser parte de la Asamblea de Concepción, ${ }^{42}$ que

36. AMI, 13, 260 (Los Habitantes de Talca en su manifiesto a los pueblos de la República de Chile, 31 de enero de 1823).

37. AMI, 13,260

38. Ibidem, $260 \mathrm{v}$.

39. Ibidem, 261

40. Ibidem.

41. Sanhueza, María Carolina, «La primera división político-administrativa de Chile. 1811-1826», Historia n. ${ }^{\circ}$ 41, vol. II, Julio-Diciembre 2008, pp. 447-493.

42. AMI, 13, 260. 
en ese momento había retirado sus representantes del Congreso. El anuncio unánime vino a demostrar que, más allá de las divisiones internas de la élite talquina, los deseos de dicha comunidad volvieron invisibles sus diferencias conceptuales e ideológicas, demostrando que cuando un grupo de individuos tiene deseos cercanos entre sí a un centro de gravedad, la sensación de poder será aún más importante. ${ }^{43}$ El objetivo de la comunidad era una mayor cuota de representación, de mayor participación política a nivel local, y que los gobiernos del momento no actuasen bajo un modelo centralista.

La separación del departamento de Talca de la provincia de Santiago y su unión a Concepción fue un reflejo más del desorden originado por el fin del régimen de O'Higgins, y puso en evidencia el modo en que las provincias y los departamentos emergían luego de cuatro años de letargo. Desde Concepción emanó una declaración conjunta con Talca, en la cual se señalaba que:

quando conozcamos que el sistema de igualdad esta conforme sin que unos pueblos quieran tener más representación que otros: quando observemos que el de Santiago no intente contar justicia, la preponderancia en dominio y representación [valida] del Capitalismo; y quando a esta consecuencia veamos instalado un gobierno central adornado del consentimiento y libertad general, entonces será cuando las provincias devan de ver a su antiguo Estado. ${ }^{44}$

La transición desde el mundo colonial, más vinculado al desarrollo regional y a los espacios locales a través del funcionamiento de los cabildos, estaba colisionando directamente con el emergente orden republicano. Un orden que era regulador, reordenador, y que estaba en formación. Las provincias, partícipes activas del proceso de independencia, no estaban dispuestas a entregar sus atribuciones ni sus fueros y abogaban por una transición que tomara en cuenta sus prerrogativas.

Ahora bien, en el interior del departamento de Talca la política seguía su camino en paralelo a los conflictos nacionales aunque no muy alejada de estos, siendo recurrente los roces entre el cabildo y los gobernadores. En abril de 1823 llegó a la ciudad Manuel de Quintana y Bravo, definido como un «hombre despótico y atrabiliario». ${ }^{45}$ La llegada de este gobernador puso nuevamente en entredicho la autoridad del cabildo, que veía frustrado su deseo de ser el organismo detentor de la competencia de nombrar a sus representantes. El carácter de Quintana y Bravo provocó roces entre los vecinos, y algunos escalaron a niveles violentos. A pesar del descontento social originado por el actuar del gobernador, Ramón Freire, el nuevo Director Supremo, lo respaldó manteniéndolo en sus funciones. Sin embargo, meses más tarde el gobernador renunció debido a las presio-

43. A propósito, James March desarrolla el rol de los deseos en el poder individual, señalando que «ventajas considerables ventajas vienen de tener deseos que se posen cercanos a los centros de gravedad del resto del sistema. Por el contrario, los individuos que tengan deseos que se posicionen lejos del centro de gravedad, experimentará una persistente pérdida de poder, March, James, Multiple Actors..., cit., p. 144. [traducción del autor]

44. AMI, 13, 265v. (Declaración de la asamblea de Concepción, 7 de marzo de 1823).

45. Opazo Maturana, Gustavo, Historia de..., cit., p. 254. 
nes ejercidas por los miembros del cabildo. Esto nos lleva a inferir que a pesar de la imposición de cargos públicos venidos desde la capital, la ciudadanía no se mostraba totalmente reacia a ellos. Si bien el deseo de la población era que un talquino accediera a ese puesto de poder, no se mostraron intransigentes ante un buen gobierno local, aunque fuese impuesto. Creemos que en este caso fueron los defectos y el comportamiento de la autoridad los que gatillaron la resistencia entre los vecinos, y sin ellos era prácticamente inviable gobernar.

De esta manera es posible notar que los conflictos a escala local reflejaron la crisis de gobernabilidad existente en Chile luego de la abdicación de O’Higgins. En la coyuntura política el intento moralizador de la Constitución de 1823 fracasó y a principios de 1825 el Congreso se declaró en desorden y bancarrota moral. La Provincia de Concepción retiró a sus diputados y estableció su propia asamblea provincial, y lo mismo pasó con Coquimbo un mes más tarde. ${ }^{46}$ Chile volvió a desmembrarse en tres provincias, aunque aún permanecía Ramón Freire en el poder. Talca mantuvo su posición de unidad junto con Concepción, pero nuevamente un conflicto pondría a la ciudad en una posición de rebeldía frente a Santiago y otras provincias. Este será un momento crucial de la historia de Talca post-independencia.

\section{El debate: Talca, ¿Departamento o una Provincia?}

Con posterioridad a la caída de O’Higgins emergió entre los juristas y personeros políticos la figura de Juan Egaña, quien en 1823 elaboró un proyecto político constitucional conservador. El carácter moralista de este proyecto llevó a que esta nueva Carta Fundamental fuera condenada, declarada inadecuada para Chile y nula a fines de $1824 .{ }^{47} \mathrm{El}$ texto generó hostilidad en los sectores liberales que abogaban por otra forma de hacer política, vinculada a la nueva tendencia de ese entonces: el federalismo. ${ }^{48}$

En 1826 el federalismo logró captar el apoyo de distintos representantes políticos del país. En las sesiones parlamentarias del año 1826 el régimen federal emergió como postu-

46. Collier, Simon, Historia de Chile... cit., p. 287.

47. Collier, Simon, Ideas... cit., p. 266.

48. El federalismo en América Latina ha despertado interés de variados historiadores, especialmente en los países en que surtió efecto en la posteridad. Para el caso mexicano, desarrollado por Josefina Zoraida Vásquez, es que la «federación fue la opción que salvaguardó la unidad en 1824 al responder al regionalismo, verdadera fuerza política al derrumbarse el intento monarquista que buscaba conservar el viejo orden novohispano». Es posible aseverar que el regionalismo, para el caso mexicano tuvo relevancia en la consolidación de la independencia. Para el caso argentino, de acuerdo a José Carlos Chiaramonte, es posible notar una inestabilidad propia de una variedad de provincias que ejercían presión a la provincia de Buenos Aires. Desde 1810 hasta 1831, experimentos provisorios de cartas fundamentales, intentos unitarios de las mismas y la posterior contienda entre federales y unitarios complejizaron los primeros intentos de organización estatal en el Río de la Plata. Finalmente, a través de un pacto federal encabezado por Juan Manuel de Rosas, se logró tibiamente instaurar un sistema confederado que caería luego de 1852. Estos análisis están presentes en Carmagnani, Marcello (coord.) Federalismos latinoamericanos: México/Brasil/Argentina, México, Fondo de Cultura Económica, 1993, pp. 15-132. 
ra hegemónica. ${ }^{49}$ En las provincias se miraba con expectación el proceso pero también con ciertos recaudos, dadas las marcadas diferencias económicas y de poder existentes entre los territorios. Este cambio de paradigma vino también a proponer un cambio político y administrativo a nivel nacional, el que sería a la postre, el principal conflicto que viviría la ciudad de Talca tras la independencia.

A inicios de 1826 llegó a Talca un comunicado que provocó malestar y exaltación política y social. Desde la capital se había determinado llevar a cabo una reforma política administrativa dirigida a dividir aún más el mapa de las provincias de la naciente república. Estas nuevas provincias se desmembraron de las provincias históricas con preponderancia hasta ese momento: Coquimbo, Santiago y Concepción. Por ley del 30 de agosto de 1826 el país fue dividido en ocho provincias. El artículo primero de ésta señalaba así los límites de la cuarta provincia: «Desde la orilla sur del río Cachapoal hasta el río de Maule. Esta provincia se denominará la provincia de Colchagua, su capital la villa de Curicó», ${ }^{50}$ tal como podemos apreciar en la figura 1 , donde se puede identificar la capital de la provincia en el centro y a la ciudad de Talca en el extremo sur de la misma.

La división territorial descolocó a los talquinos, que a partir de ese momento intentaron buscar una salida que estuviera de acuerdo con sus intereses. Un cabildo dominado por liberales, conservadores y estanqueros debió hacer a un lado sus divisiones internas y unirse para hacer frente a una determinación gubernamental que consideraban injusta. El gobernador del departamento envió a Santiago una misiva que los talquinos redactaron el día 16 de mayo de 1826, luego de haber conocido el decreto federal, señalando que «grandes son señor las razones en que firma el vecindario la esperanza de conseguir la gracia que implora y grandes los sentimientos que de dar curso el decreto reciviría una población tan comprometida y empeñada en la época de la revolución...». ${ }^{51}$ Esta primera afirmación era el fiel reflejo de un claro auto-reconocimiento de Talca por parte de sus vecinos y su participación activa en las guerras de independencia. Entendemos que este fue uno de los aspectos que incrementó el orgullo local y su deseo de preponderancia en el espacio regional de la naciente república.

La misma misiva de los talquinos señala que, «siendo su rival que no le iguala en servicios, lleva lo que tramposo puede disputarle por su localidad y circunstancias», ${ }^{52}$ en una clara alusión a la ciudad de Curicó que para muchos talquinos no era la ciudad indicada para poseer el control y comandancia de la naciente Provincia de Colchagua. Depender de Curicó implicaba «el más injustificable de los atropellos, la más grosera de las burlas, la insolencia más intolerable...»;53 aseveraciones surgidas del orgullo herido, de

49. Stuven, Ana María y Gabriel Cid, Debates Republicanos Volumen 1, Santiago, Ediciones UDP, 2012, p. 386.

50. Donoso, Ricardo, «La creación de la provincia de Talca», Revista Chilena de Historia y geografía, 1933, Santiago, p. 421.

51. AMI, 13, 399 (Misiva que encabeza el oficio que los talquinos envían a Santiago luego de conocido el Decreto federal, 20 de mayo de 1826).

52. Ibidem.

53. Donoso, Ricardo, La creación ..., cit., p. 422. 
un atentado a su honor local, que para la élite local se vinculaba a su adhesión a la causa de la libertad y el respeto de los pueblos que conforman una nación. Al parecer, para los talquinos los curicanos desempeñaron en las guerras de independencia un papel sustantivamente menor. Si por un lado estaba el argumento patriótico para el descontento social, también existía una rivalidad con su vecina ciudad del norte: Curicó. Una pequeña villa fundada en el mismo período, como resultado de la política de control de los cuerpos y del vagabundaje propio de las zonas rurales. Históricamente, Talca tuvo un crecimiento mayor que Curicó, en cuanto a población y a riquezas.

\section{Provincia de Colchagua en 1826}

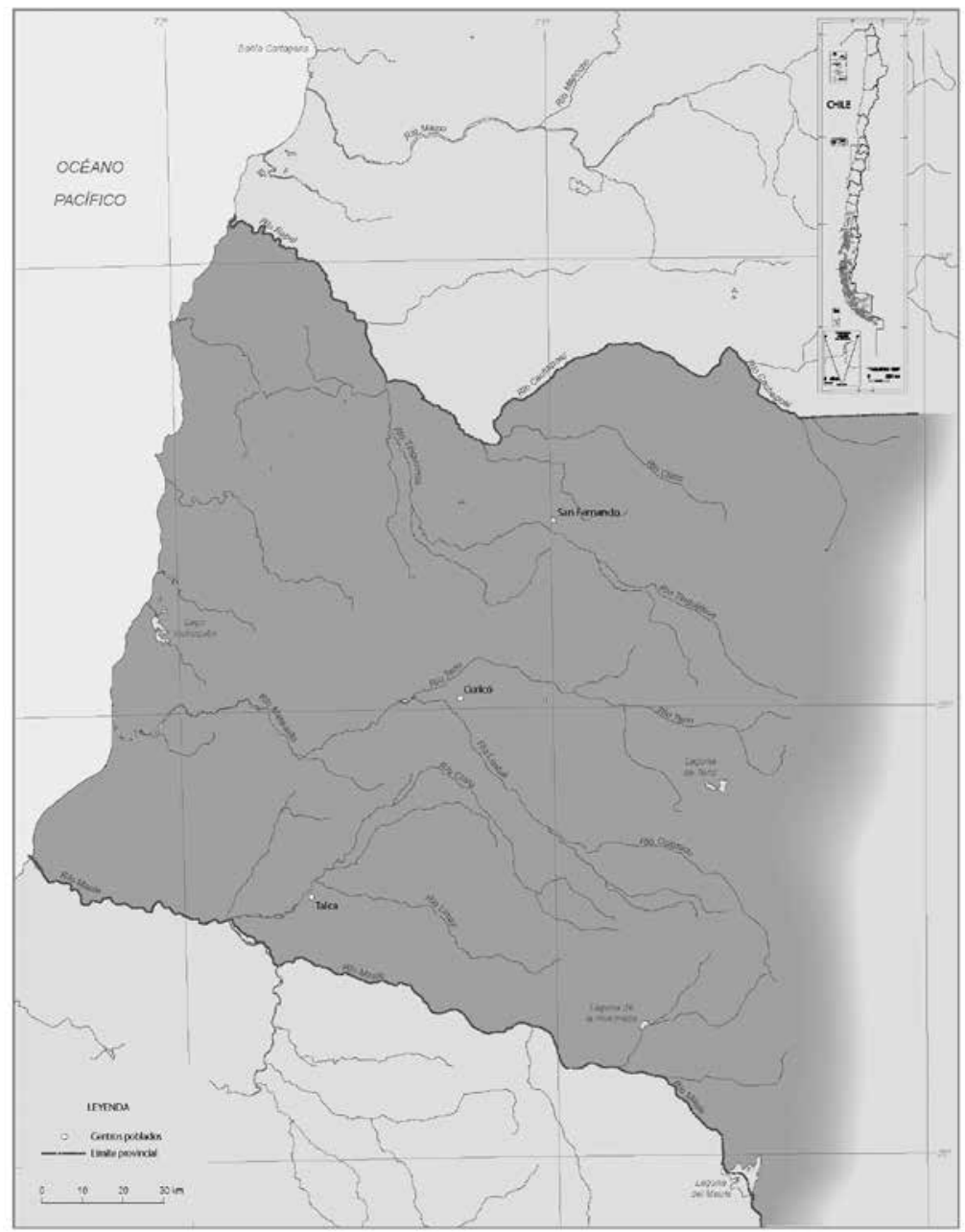

Figura 1. Sagredo, Rafael, José Ignacio González y José Compan, La política en el espacio. Atlas bistórico de las divisiones político-administrativas de Chile. 1810-1940, Santiago, Centro de Investigaciones Barros Arana, p. 164. 
La relegación de Talca a una posición secundaria fue uno de los puntos clave para los talquinos. Ahora bien, ¿Por qué la élite talquina impone una posición transgresora frente al orden centralista? Podríamos inferir de acuerdo a lo que nos señalan los documentos que la nueva división político administrativa no reconocía ecosistemas naturales, dinámicas socio-espaciales, ni tampoco la historia de progreso experimentado por la ciudad hasta ese momento. Durante la Colonia Talca encabezó el Corregimiento del Maule, punto límite entre las provincias de Santiago y Concepción. La ausencia del reconocimiento histórico concretado en esta división provocó un descalabro social y la ira del pueblo talquino. A pesar de esto, es posible observar que operó una lógica de ubicación estratégica, puesto que se puede percibir que Curicó ocupaba la posición geográfica central dentro de la Provincia de Colchagua, al contrario de Talca que ocupaba el extremo sur de la provincia. Así, no era de extrañar que Curicó fuera nombrada capital.

El evidente diálogo existente entre Talca, Curicó y Santiago se vio reflejado en los distintos oficios y misivas que fueron enviados desde Talca a los otros dos destinatarios. No obstante, es posible realizar una doble lectura de este conflicto: en primer lugar, el reconocimiento talquino a la autoridad central, sin importar la coyuntura política existente, a través de continuas comunicaciones entre el gobernador, los representantes y el Ministerio del Interior. En segundo lugar, el desconocimiento de la autoridad de Colchagua y su capital de Curicó con respecto al Departamento de Talca. Uno de los casos dignos de análisis fue el de la elección de diputados, momento en el cual las demandas talquinas y el desconocimiento de una autoridad mayor les llevó a entablar una posición de rebeldía de carácter simbólica frente a la división territorial.

El día 20 de mayo de 1826, al momento de elegir diputados para el nuevo Congreso, el pueblo se reunió para presenciar el escrutinio de los sufragios y aprovechó de manifestar «sus particulares sentimientos» a partir de una «comunicación remitida por el Governador de Curicó al de este pueblo», donde «se transcribe un decreto expedido por S.E para que los delegados y demás agentes subalternos se dirijan en todos los asuntos en serbicio al delegado o gefe político en la delegación a que pertenezcan». ${ }^{54}$ Entre los talquinos solo se debía obediencia a la ciudad de Curicó, señalando además que existía una «prohibición absoluta de entenderse con el supremo govierno hasta en sus casos particulares». ${ }^{55}$

Los talquinos, sin embargo, intentaron conformar informalmente su propia provincia, transgrediendo los decretos leyes provenientes desde la capital y como forma de presionar al gobierno central. Los argumentos sociales, económicos y geográficos fueron claves para llevar a cabo un alegato directo frente al Ministerio del Interior. Los ríos navegables del Maule eran epicentros del desarrollo y crecimiento de la zona; el auge triguero del siglo XVIII, beneficiado por la presencia de importante mano de obra, había potenciado la economía local, incluso la existencia del astillero del Maule vinculado

54. Ibidem, 400. (Respuesta a la comunicación del Gobernador de Curicó por parte de la sala de representantes de Talca, 20 de mayo de 1826).

55. Ibidem, 400 . 
directamente a Talca fue otro argumento. No obstante, para los talquinos el argumento demográfico fue el más significativo:

Talca excede a Curicó en quatriplicada población; pues no dando alguno tres mil abitantes a aquel, calculan todos en el nuestro más de diez mil. Quando no quiera que para los destinos públicos sea mas escequible elegir con mas asiento en el mayor numero, porque aunque se diga que en todo el cuerpo de las provincias pueden elegirse, no todos para acsidentales empleos dejan la atención de sus seguras propiedades; no podrá negarse la mayor esposicion en todo lo que exigen los casos de premura en el pueblo que por su mayor vecindad ofrece brasos y demás aucsilios sin la tardanza de buscarlos en el campo y pueblos de su dominio. ${ }^{56}$

La cantidad de población y el acceso a la mano de obra era una de las razones que manejaban los talquinos al momento de creer que la decisión de Santiago era errónea, sosteniendo además que «este pueblo ha prestado mas brasos, mas dinero y mas aucsilios que ninguno de la república desde el Maipú al sur». ${ }^{57}$ Casimiro Albano, apoderado de la población talquina durante esta controversia señaló que:

Curicó ni es, ni puede ser el punto céntrico de la Provincia, ya se le considere con respecto a su posición geográfica, ya a sus relaciones y recursos. La demarcación de la 4. ${ }^{\text {a }}$ Provincia, según el documento ya citado, yace entre la banda occidental del Cachapoal y oriental del Maule, cuya distancia media será el Chimbarongo, y no Curicó, de quien dista sobre veinte leguas sud. Menos es el de sus relaciones porque Curicó tendrá siempre la necesidad de llevar sus frutos a Talca para expenderlos, y jamás ésta a aquel tal es una ventajosa situación..$^{58}$

Entre los talquinos se creía que dada su posición entre Concepción y Santiago, y por sus

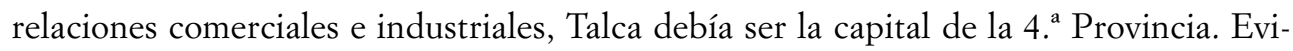
dentemente, ante la situación de que sus argumentos no fuesen reconocidos, la población estaría en condiciones de escindirse y de igual forma definir los límites administrativos de su provincia, a pesar de que éstas tuvieran un carácter informal.

El día 27 de abril de 1827, la sala de representantes de la ciudad acordó reconocerse por separado de la provincia de Colchagua a la que se habían visto incluidos por ley de demarcación. Procedieron a formar una Asamblea Departamental compuesta por Diputados electos según la ley para el Congreso y para las Asambleas Provinciales. ${ }^{59}$ Los aristócratas Pedro Nolasco Vergara, Matías Silva, Juan Crisóstomo Zapata, entre otros, fueron los que dieron el vamos a dicha declaración «jurando dar sus vidas y sus haciendas por la independencia». ${ }^{60}$ Una lucha directa al interior de la, ahora autónoma, Asamblea

56. AMI, $13,402$.

57. Ibidem.

58. Ibidem (Locución de los representantes junto a Casimiro Albano, Talca, 20 de mayo de 1826).

59. Ibidem, 413 (Declaración de la Sala de Representantes de Talca copiada por la Gobernación de Talca al Ministerio del Interior, Talca, 28 de abril de 1827).

60. Opazo Maturana, Gustavo, Historia de..., cit., p. 258. 
de Talca, que según Opazo, siguió funcionando regularmente, por ejemplo el día 22 de mayo discutió el reglamento interior y se nombraron comisiones, para luego fijar los límites y la división del departamento. ${ }^{61}$ Los ciudadanos de Talca estaban transgrediendo el orden político y administrativo pero, al mismo tiempo, se valieron de los mecanismos constitucionales de elección de diputados y de los procedimientos de escrutinio establecidos por ley; la lealtad de los ciudadanos hacia la patria no estaba puesta en duda, eran las malas decisiones administrativas las que provocaron descontento entre la élite.

La decisión de la asamblea talquina era básicamente transformarse en una Asamblea Provincial autónoma de la de Colchagua. Bajo ninguna circunstancia es posible notar un intento insurgente ni revolucionario frente al orden nacional, sino que a través de la normativa vigente se intentó construir un nuevo orden político administrativo interno constituido por los ciudadanos de Talca. Los talquinos buscaron una solución política a una decisión que, de acuerdo a su cosmovisión, habían considerado injusta.

\section{El advenimiento de Portales y la creación de la provincia de Talca}

La Constitución de 1828 no vino a cambiar la división político administrativa que había sido ideada dos años antes. No obstante, parecía ser que este gobierno podría calmar las movidas aguas de años anteriores. Simon Collier lo define como un buen gobierno con ideas de paz surgidas de entre el presidente Francisco Antonio Pinto y Joaquín Prieto.62 Para Talca, el conflicto con Santiago y Colchagua se prolongó, puesto que no hubo iniciativa gubernamental para llevar a cabo un cambio. El cabildo de Talca mantuvo su entereza y su decisión y ante un reclamo del juez de letras de Colchagua, el pueblo manifestó su descontento por la ley de demarcación y al considerarse pendientes sus reclamos ante la representación nacional, no se consideraba parte de la provincia, ${ }^{63}$ por lo que la competencia del juez ante los talquinos era inexistente. La intransigencia territorial y administrativa se mantuvo y con ella las operaciones del cabildo y de la sala consistorial. Estas siguieron su constante elección de representantes como si Talca hubiese sido una provincia aparte.

Los sucesos ocurridos en el año 1829 fueron determinantes para el futuro de la naciente república chilena. Distintas tensiones existentes entre liberales y conservadores, así como también rivalidades entre Santiago y los representantes del ejército del sur, instalado en Concepción, llevaron a una crisis que se vería detonada en septiembre de 1829 con una irregularidad en la elección del vicepresidente en un Congreso dominado por los liberales. ${ }^{64}$ El problema de la elección presidencial motivó a que las provincias del sur, Concepción y Maule, vinculadas al sector conservador, se levantaran contra el Congreso

61. Ibidem, p. 259.

62. Collier, Simon, Ideas..., cit., p. 291.

63. Donoso, Ricardo, «La creación...», cit., p. 423.

64. Collier, Simon, «Historia...», cit., p. 55. 
Soberano. Evidentemente existían problemas de fondo y rivalidades arrastradas desde inicios del período de los ensayos constitucionales, siendo la irregularidad de esta elección y la designación presidencial del candidato que obtuvo la cuarta mayoría de votos, los que detonaron la movilización militar desde el sur.

Desde Cauquenes, la capital de la provincia de Maule ${ }^{65}$ que ya era adepta a la causa insurreccional se envió al departamento de Talca a un plenipotenciario, Don Ignacio Molina, para buscar solicitar «la concurrencia de Talca a formar una causa con las Provincias de Maule y Concepción para exijir la observancia de la Constitución quebrantada por la Representación Nacional» ${ }^{66}$ Luego de la reunión y la observancia de la petición de Molina, el Gobierno Departamental de Talca, teniendo en consideración que su antiguo conflicto territorial no había tenido solución mediante una nueva ley de Demarcación y que sus recursos a la Representación Nacional aún se hallan pendientes, decidió no reconocer al recientemente nombrado presidente de la República, ${ }^{67}$ uniéndose de este modo a la acción proveniente desde el sur que desembocó en la Guerra Civil de 1829-1830. ${ }^{68}$

El descontento de los vecinos talquinos, además de la poca probidad en el actuar del gobierno con respecto al respeto de las mayorías en las elecciones llevaron a que la población local, quizás buscando algún beneficio territorial, formara parte de la oposición. No hay dudas de que por la mente de algunos talquinos podría haber pasado apoyar al otro bando para así, en el futuro, obtener réditos positivos.

Pasado lo más complejo del conflicto, luego de la victoria Conservadora en Lircay el 17 de abril de 1830, a escasos kilómetros al norte de Talca, la política local de la ciudad se dirigió con todos sus esfuerzos al restablecimiento de los vínculos comunitarios. La Municipalidad de Talca, el día 28 de Marzo de 1831, decidió elegir a Pedro Nolasco Vergara como su gobernador. La posición de Nolasco Vergara fue conciliadora y abogó por políticas locales, tales como la iniciativa para la creación del Instituto Literario y un Colegio a través de una Junta de Educación. ${ }^{69}$ El gobierno de José Joaquín Prieto comenzó a controlar aún más las atribuciones de los gobiernos locales, defendiendo y promoviendo el centralismo que será característico de nuestro país desde ese entonces. Las asambleas provinciales perdieron su protagonismo y la figura del Intendente quedó al mando

65. Diego Barros Arana señala al respecto que «Aquel movimiento insurreccional fue secundado inmediatamente por la asamblea provincial de Maule. Reunida ésta extraordinariamente en Cauquenes el 12 de octubre bajo la presidencia de don Ignacio Gana, hizo en un acta declaraciones algo diferentes en la forma, pero idénticas en el fondo, desconocimiento en ellas la validez de la elección de Vicepresidente de la República hecha por el Congreso, y negando la obediencia a éste y a las autoridades que emanasen de sus actos» Barros Arana, Diego, Historia General de Chile Tomo XV, Santiago, Dibam-Universitaria, 2005, p. 279.

66. AMI, 28, 246 (Oficio de José María Silva y Cienfuegos al Ministerio del Interior, Talca 18 de octubre de 1829).

67. Ibidem 247 (Oficio del Gobierno Departamental de Talca al Ministerio del Interior, Talca, 16 de Octubre de 1829).

68. Un aspecto llamativo al respecto es que en el Volumen 13 correspondiente a la Intendencia de Talca entre los años 1810 y 1831 hay un vacío de documentos relativos a la Guerra Civil.

69. AMI, 117, 2-2v (Oficio de la Junta de educación de Talca al Ministerio del Interior, Talca 10 de enero de 1832). 
de la provincia «de quien es ajente natural e inmediato [del Presidente] y puede ser reelegido para el cargo infinitas veces». ${ }^{70}$

En Junio de 1831, nuevamente ante un requerimiento del juez de Colchagua para que se le enviaran las causas que hubiese de los reos confinados en la cárcel de Talca, se le contestó que no estando reconocida su autoridad en el Departamento no se podía dar cumplimiento a su petición. ${ }^{71} \mathrm{El}$ conflicto permanecía a pesar del naciente orden autoritario existente durante ese período. Todo indicaba que la única solución era que la voluntad de Santiago permitiera y prometiera lo que los talquinos tanto anhelaban.

Finalmente, Diego Portales, ministro de Interior, accedió a la petición talquina a cambio de que prometieran jurar la Constitución que se encontraba en proceso de redacción. ${ }^{72}$ De esta manera se puso fin al conflicto que hasta 1833 mantuvo al Departamento de Talca en una posición de intransigencia política y social. Si bien nunca pasó a mayores, esta situación complicó el orden de la administración pública interior en un Estado en proceso de formación. En medio de los festejos de la ciudadanía nació la Provincia de Talca que, de acuerdo a la figura 2, se extendía desde el Río Lontué por el norte hasta el Río Maule por el sur, división histórica del departamento durante la década de 1820. Así, Talca no pasó a ser capital de la provincia de Colchagua sino que obtuvo una provincia propia para su territorio departamental.

70. López Taverne, Elvira, El proceso de Construcción de Estado en Chile. Hacienda pública y Burocracia (1817-1860), Santiago, Dibam, 2014, p. 167

71. Donoso, Ricardo, La creación..., cit., p. 424

72. Opazo Maturana, Gustavo, Historia de..., cit., p. 263-264 
Provincia de Talca en 1833

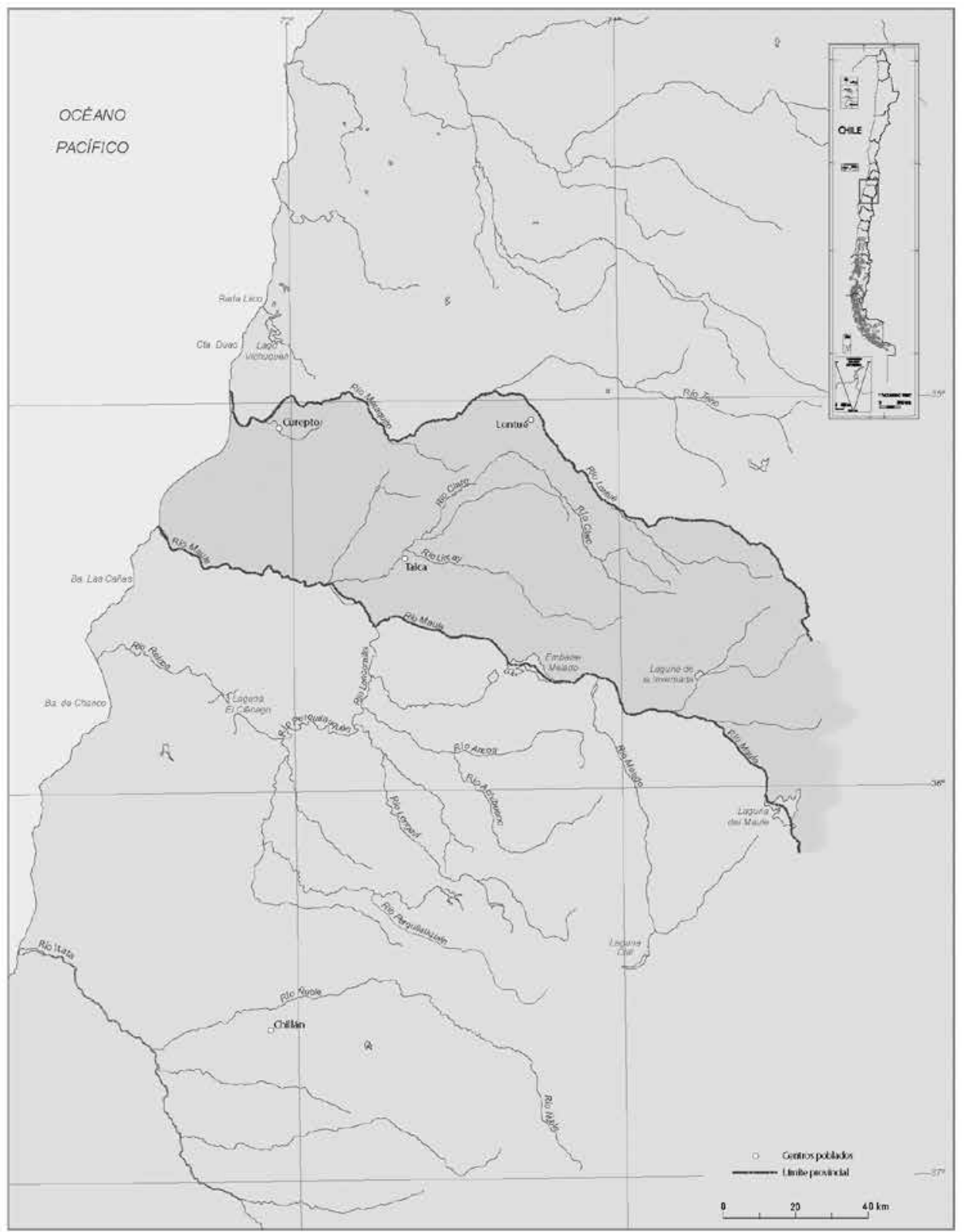

Figura 2. Sagredo, Rafael, José Ignacio González y José Compán, La política en el espacio. Atlas bistórico de las divisiones político-administrativas de Chile. 1810-1940, Santiago, Centro de Investigaciones Barros Arana, p. 178. 


\section{Conclusiones}

El conflicto originado en Talca por la división político-administrativa de 1826 tuvo su punto final el año 1833 cuando el ministro Diego Portales, al ver que la sociedad talquina no daría su brazo a torcer, propuso la creación de una nueva provincia, cuya capital sería la ciudad de Talca, a cambio de la jura de la Constitución de 1833. La élite talquina en conjunto con el pueblo apoyó la propuesta y se dio por finalizado el conflicto. Esto demuestra que la élite local estaba dispuesta a jurar una carta fundamental del todo centralista y que coartaba las potestades provinciales a cambio de lograr su posicionamiento político y territorial entre Santiago y Concepción. Una certera demostración de que no existían otras intenciones implícitas en las constantes tomas de decisiones de la sala de representantes del cabildo de Talca.

En línea con lo estudiado sobre la toma de decisiones políticas y el poder que en ellas se juega, es posible notar que hablar de una sola élite nos lleva a un error conceptual y práctico. De las decenas de familias importantes y con participación política antes y después de 1810, observamos que a pesar de sus vínculos matrimoniales y económicos existen marcadas diferencias ideológicas. Las familias marcadamente realistas y las más patriotas debieron enfrentarse en la sala capitular del cabildo. Los resentimientos del pasado y las luchas por obtener cuotas de poder eran relevantes, pero los factores externos fueron determinantes en la unidad de las pautas y objetivos que estas familias buscaron conseguir. La política nacional, el desorden político-administrativo y las medidas administrativas, como la nueva demarcación, fueron un factor de unidad en la toma de decisiones de la ciudadanía talquina. De esta forma, podemos inferir que la lucha por ser provincia y capital podía significar en la mente de los talquinos de aquel entonces un mayor acceso al poder y una mejora económica evidente en un mercado que había pasado zozobras luego de años de guerras y bandidaje.

La rebeldía simbólica del pueblo talquino, sumada a su intransigencia política marcaron la pauta sobre cómo fueron llevadas a cabo las políticas locales en este período. El conflicto reflejó dos aspectos que consideramos claves: la poca gobernabilidad existente en el período en cuestión por parte de Santiago y su administración pública y, por el otro lado, el deseo de ser y parecer propio de la élite talquina. Este deseo de ser y parecer fue el que motivó a la élite a oponer resistencia al gobierno, al mismo tiempo que intentó instaurar un orden propio independiente del que fue administrativamente impuesto. Si bien la rebeldía talquina se prolongó por más de 7 años, esto no fue motivo para que no hubiera participación activa por parte de los talquinos a través de Casimiro Albano y José Ignacio Cienfuegos en los congresos y en las discusiones legislativas nacionales. Talca envió constantemente representantes a través de su asamblea obviando la autoridad de Curicó en Colchagua.

La toma de decisiones de los vecinos se percibió en un sentido práctico, buscando la reconfiguración provincial de Colchagua con el fin de que su ciudad fuese designada como capital. Conseguida la creación de la provincia de Talca se desarticuló la unidad de la élite y la posición de fidelidad, celo y patriotismo al Estado-Nación chileno consolida- 
do luego de Lircay en 1830. La dualidad entre liberales y conservadores se desarticuló en 1833, pasando a tener hegemonía el bando conservador por ser el que obtuvo el poder luego de la guerra civil. A pesar de la división y la hegemonía de un sector de la aristocracia, la élite talquina había conseguido su anhelada posición de poder por el simple hecho de mantenerse unida y consensuada en una decisión política innegociable por casi una década.

La jura de la Constitución de 1833, como resultado de la aceptación de Portales en nombrar a Talca como provincia separada de Colchagua, significó el paso a un lento proceso de centralización, que conllevaría la aparición de nuevos desafíos políticos, tanto en la administración nacional como en las distintas provincias. Entender el proceso de construcción estatal en Chile nos remite a dos períodos distintos. En primer lugar, el iniciado en 1818 y finalizado en 1833 , en el cual se experimentó la inestabilidad política y una desorganización por la falta de experiencia y de certezas en la elección del camino a seguir; y en segundo lugar, el que se experimentaría luego de 1833 cuando el régimen autoritario debió sortear distintos desafíos en la administración interior de las provincias.

\section{Bibliografía}

\section{Fuentes:}

Fondo Ministerio del Interior, Archivo Nacional Histórico.

Fondo Intendencia de Talca, Archivo Nacional Histórico.

\section{Referencias bibliográficas:}

Barros Arana, Diego, Historia general de Chile, Santiago, Rafael Jover Editor, 1884-1902, 16 vols. Cáceres, Juan, Poder rural y estructura social, Colchagua, 1760-1860, Valparaíso, Ediciones Universitarias PUCV, 2007.

Carmagnani, Marcelo (coord.), Federalismos latinoamericanos: México, Brasil, Argentina, México, Fondo de Cultura Económica, 1993.

Cartes, Armando, Un gobierno de los pueblos... Relaciones Provinciales en la Independencia de Chile, Valparaíso, Ediciones PUCV, 2014.

-, «Un enfoque provincial de la construcción de Estado en Chile», Revista Historia Universidad de Concepción, n. ${ }^{\circ}$ 24, vol. 2 julio-diciembre 2017, pp. 123-143.

—, Biobio. Bibliografía histórica regional, Santiago, Dibam, 2014.

Collier, Simon, Ideas y política de la independencia chilena, 1808-1833, Santiago, FCE, 2012.

—, William Sater Historia de Chile 1808-1994, Cambridge, Cambridge University Press, 1998.

Chiaramonte, José Carlos, Ciudades, provincias y estados: Orígenes de la Nación Argentina, Buenos Aires, Ariel, 1997.

De Ramón, Armando, «Un progreso Interrumpido: El caso de Talca durante la segunda mitad del siglo XIX», Revista Eure, vol. XXI, n. ${ }^{\circ}$ 62, Santiago, 1995, pp. 33-47. 
Donoso, Ricardo, «La creación de la provincia de Talca», Revista de Historia y Geografía, Santiago, LXXIV, 79, pp. 421-426.

Edwards, Alberto, La Fronda Aristocrática en Chile, Santiago, Imprenta nacional, 1928.

Grez, Sergio, De la regeneración del pueblo a la buelga general. Génesis y evolución histórica del movimiento popular en Chile (1810-1890), Santiago, Barros Arana, 1997.

Guardino, Peter, El tiempo de la Libertad. La cultura política popular en Oaxaca, 1750-1850, UABJO-UAM, 2009.

Infante, Javier, Autonomía, Independencia y República en Chile 1810-1828, Santiago, Bicentenario, 2014.

Jaksic, Ivan; Juan Luis Ossa (editores), Historia Política de Chile, 1810-2010 tomo I, prácticas políticas, Santiago, FCE, 2017.

—, Francisca Rengifo (eds.), Historia política de Chile, 1810-2010. Tomo II. Estado y sociedad, Santiago, Fondo de cultura económica, 2018.

Larson, Brooke, Indígenas, Élites y Estado en la formación de las Repúblicas Andinas, Lima, Pontificia Universidad Católica del Perú. Fondo Editorial, 2002.

Lempérière, Annick, «¿Excepcionalidad chilena? La formación del Estado, entre revolución e institucionalización (1810-1845)», en Jaksic, Ivan, Francisca Rengifo (eds.), Historia Política de Chile, 1810-2010 Tomo II Estado y sociedad, Santiago, Fondo de Cultura Económica, 2018, pp. 23-54.

López Taverne, Elvira, El proceso de construcción estatal en Chile. Hacienda pública y burocracia (1817-1860), Santiago, Dibam, 2014.

Lorenzo, Santiago, Origen de las ciudades chilenas, las fundaciones del siglo XVIII, Santiago, Andrés Bello, 1983.

Mallon, Florencia, Campesino y Nación: la construcción de México y Perú poscoloniales, México DF, Centro de Investigaciones y Estudios Superiores de Antropología social, 2003.

March, James, «Multiple Actors. Conflict and politics», en A primer on Decision Making. How Decisions Happen, New York, 1994.

Morales Yamal, Alejandro, Gonzalo Olmedo Espinoza y Raúl Sánchez Andaur La villa de San Agustín de Talca. Origen y desarrollo entre la intención y la realidad (siglos XVI al XVIII), Talca, Universidad Autónoma-Gobierno regional del Maule, 2012.

Opazo Maturana, Gustavo, Historia de Talca 1742-1942, Santiago, Imprenta Universitaria, 1942.

Sagredo, Rafael, José Ignacio González y José Compán, La política en el espacio. Atlas histórico de las divisiones político-administrativas de Chile. 1810-1940, Santiago, Centro de investigaciones Diego Barros Arana, 2016.

Salazar, Gabriel, Construcción de estado en Chile (1760-1860): democracia de los pueblos, militarismo ciudadano, golpismo oligárquico, Santiago, Sudamericana, 2005.

Sánchez, Raúl, «Talca: Medio siglo de Oligarquía (1850-1900)», Universum, Año 7, n. ${ }^{\circ}$ 1, 1992, Talca, pp. 49-64.

Sanhueza, María Carolina, «La primera división Político-Administrativa de Chile, 1811-1826, Historia, n. $^{\circ}$ 41, vol. 2, Santiago, 2008, pp. 447-493.

Stollberg-Rilinger, Barbara, «Culture of decisión making», The German bistorical Institute London, London, 2016.

Stuven, Ana María y Gabriel Cid Debates Republicanos Volumen 1, Santiago, Ediciones UDP, 2012.

Ternavasio, Marcela, Historia de la Argentina 1806-1852, Buenos Aires, Siglo XXI, 2009

Villalobos, Sergio, Historia de los Chilenos. Tomo 2, Santiago, Taurus, 2007. 